\title{
Homeostatic and Circadian Control of Food Intake: Clinical Strategies to Prevent Overconsumption
}

\author{
V. Drapeau • A. R. Gallant
}

Published online: 30 December 2012

(C) Springer Science+Business Media New York 2012

\begin{abstract}
The current environment has a strong impact on the rise in population body weight as it provides ample opportunity to consume food, often beyond one's metabolic requirement. The homeostatic processes that regulate food intake are often overlooked or weakened in such an environment, particularly among susceptible individuals. Moreover, there is strong circadian control over food intake and the circadian system is tightly entwined in body weight regulation. Clinical nutritional and behavioral strategies can strengthen homeostatic signals of satiation and satiety and improve appetite control. Synchronizing the circadian system through exercise and regular sleeping and meal patterns may also enhance these signals. Together, these strategies can help reduce overeating episodes, particularly among susceptible individuals, and may play a role in better long-term body weight regulation.
\end{abstract}

Keywords Appetite control · Homeostatic ·

Overconsumption $\cdot$ Circadian

\section{Introduction}

The current environment is characterized by an unlimited amount and opportunity to eat a wide variety of lownutrient, energy-dense foods. As a consequence, overconsumption is common and implicated in the gradual increase in population body weight [1]. Individual day-to-day food intake is represented by a succession of eating episodes

\section{Drapeau $(\square)$}

Department of Physical Education, Laval University and The Quebec Heart and Lung Research Institute, Laval Hospital, Quebec, Canada G1V 0A6

e-mail: vicky.drapeau@fse.ulaval.ca

\section{A. R. Gallant}

Department of Physical Education, Laval University and The Quebec Heart and Lung Research Institute, Laval Hospital, Quebec, QC, Canada which are differentiated by key features such as frequency, size, composition and timing. All of these features can play a role in excess energy intake. The driving forces that control overall food intake, and hence overconsumption, are complex and involve psychobiological processes that maintain body energy stores and nutrition (homeostatic), that motivate eating high energy dense foods (hedonic), and that ensure appropriate timing of ingestion (circadian system) [2]. In the context of obesity and overconsumption, the homeostatic drivers of food intake are of high interest. In addition, this 'obesogenic environment' implies that not all individuals become obese in this environment and emphasizes the need for specific strategies to prevent weight gain, particularly in more susceptible individuals. One strategy could be to develop an intervention to enhance the homeostatic signals and circadian control of food intake with the aim to improve satiation and satiety, and thereby reduce the risk of overeating. This article will briefly discuss the homeostatic and circadian control of food intake, describe individuals at risk for overconsumption and suggest clinical strategies to enhance these biological processes, to reduce the risk of overconsumption and ultimately, to prevent weight gain.

\section{Appetite Control}

Short-Term and Long-Term Homeostatic Appetite Control

Homeostatic control of appetite involves various physiological processes that initiate and terminate feeding (satiation) and suppress inter-meal hunger (satiety) in order to regulate body weight. This discrete feeding cycle has previously been labeled the satiety cascade [3]. Sensory information derived from chewing and tasting, i.e., the cephalic phase, provide early neural and humeral responses to feeding, such as the release of pancreatic hormones [4] and could produce a very early satiation response [5]. Then, gastric distension, 
influenced by food volume, also creates an important early satiation. Mechanoreceptors in the stomach relay information to the brain via sensory afferents [6]. Prior to full gastric distension, the stomach empties into the intestine at a rate inversely related to the energy content of the meal [7•] and nutrients in the gut trigger the release of satiation peptides [8]. Neuropeptides and neurotransmitters elicit endocrine and neural actions and transmit information to the central nervous system to initiate, maintain or terminate feeding (for more details see $[7 \cdot, 8])$. Some of these peptides and neurotransmitters influence appetite through increasing dietinduced thermogenesis via activation of the sympathetic nervous system [9]. Taken together, oro-sensory, gastric and intestinal signals, which represent episodic control, interact on their effect on early satiation in humans [10]. Although some of these processes are not strictly under homeostatic control, i.e., gastric distension, the energy content of the meal does effect early satiation [7•]. In addition, these meal-related humeral signals can be modulated by the more tonic, or long-term, homeostatic signals which are influenced by body energy stores, namely leptin, insulin $[11,12]$, and ghrelin [13]. For example, there are synergistic effects between leptin and both cholecystokinin (CCK) and GLP-1, gut peptides involved in satiation [14, 15]. Insulin has also been shown to enhance the effect of CCK [16] and GLP-1, an incretin hormone, i.e., is activated by nutrients to stimulate the release of insulin [17]. These select examples of the interaction between short- and long-term control lay the foundation for intervening on a meal-by-meal basis in the prevention of overconsumption and, in turn, weight gain.

\section{Circadian Control of Food Intake}

The circadian system is often neglected in appetite research yet there is a direct relationship between the control of food intake and the biological clock [18]; feeding is highly cyclic and constricted to the daytime. Feeding and regular meal times can even adjust circadian rhythms [19]. In addition, many aspects of appetite control follow ultradian, recurrent cycles throughout the day, and circadian rhythms. The secretion of ghrelin is a good example of this. This orexigenic hormone is involved in food intake and has a distinct preprandial peak followed by a postprandial decline [20] proportional to the ingested calories [21]. Ghrelin secretion is highly influenced by the timing of habitual eating patterns and oscillates despite the lack of external food and timing cues [22] which persist even during 24-h or fasting, i.e., in the absence of meals [23]. In addition, there is evidence that ghrelin secretion can be entrained in humans by varying meal patterns [24]. Besides ghrelin, other appetite-related hormones show both ultradian and circadian rhythms, e.g., leptin [20], pancreatic peptide (PP) [25], gastric inhibitory peptide [26]. It has also been proposed that food consumed in the morning is particularly satiating compared to food consumed in the evening [27-29]. Accordingly, the rate of gastric emptying for solids was reported to be higher in the evening compared to the morning [30]. These results provide evidence that internal biological factors can influence feeding through circadian control, regardless of nutritional status, and that factors mediating satiation and satiety may be more effective at different times of the day. Moreover, individuals with altered circadian rhythms are more susceptible to poor appetite control, and consequently, overeating [31, 32]. The disruption of the circadian system has homeostatic implications as it has been considered a novel factor in the aetiology of obesity [33.] and has metabolic and cardiovascular consequences [34]. These results indicate the circadian system has a strong influence on eating, satiety and homeostatic processes.

\section{Susceptibility to Overeating - Are we all Equal?}

Not surprisingly, obese individuals show differences in the humoral control of appetite. Leptin and insulin resistance are common in obesity and, considering their important functions in homeostatic processes, may play a role in poor appetite control [11]. Moreover, administration of ghrelin has been shown to stimulate eating more in the obese than the lean [35], and the former also show an attenuated postprandial decline in ghrelin [36]. Thus, the obese state, per se, is associated with an internal physiology that likely influences, if not leads to, poor appetite control and overconsumption.

It is not only the obese state that may interfere with appetite control. The 'low satiety phenotype' (LSP) are individuals who report difficulties in recognizing their appetite sensations either before or after a meal $[37,38]$. This phenotype encompasses individuals with a large range of body weights [37] and not all obese individuals present this phenotype [39]. These individuals have been characterized with increased perceived anxiety and with a blunted cortisol response to a meal [39]. Weakened appetite signals among these individuals can increase their susceptibility to overeating $[40,41]$.

Restrained individuals, i.e., those with a constant cognitive control over food intake, could represent another vulnerable phenotype to overeating [42]. There is evidence of reduced satiety efficiencies and reduced satiety among restrained females [43, 44]. Others, however, have reported no relationship between restraint and self-reported appetite sensations or energy intake after a standardized meal [38, 41, 45]. Although inconsistent, some studies [46, 47], have shown a relationship between dietary restraint and weight gain, suggesting that restriction could be a difficult behavior to maintain and may trigger overeating episodes.

There is evidence that individuals with high disinhibition, i.e., overeating tendencies [48], have abnormalities in self- 
regulation of eating $[49,50]$ and show a reduced reported satiety response to a meal when overfed [51]. Association studies have also shown that individuals with diminished satiety responses (LSP) are characterized by increased measures of disinhibition [38, 39, 52]. In addition, a blunted CCK response to a meal was reported among women with both high dietary restraint and disinhibition [53] - an unhealthy eating behavior trait which is also associated with higher body weights, particularly with rigid control over eating [54].

Individuals reporting short sleep duration and poor sleep quality could also be at higher risk of overeating. Lack of sleep is directly related to hormonal changes favoring increased appetite [55] and may impair the action of leptin [56]. Sleep is also consistently related to higher body weights [57]. Additionally, there is a strong two-way relationship between sleep and circadian synchronization and circadian dysregulation could mediate the effects on appetite. Indeed, sleep loss can attenuate the circadian profile of leptin [58]. Moreover, individuals who eat at night or present the night eating syndrome (NES) [59], a phenotype characterized by a circadian delay in food intake, report low appetite in the morning and increased late-night cravings [60]. They also show a blunted appetite response to a test meal, particularly in the evening [31] and attenuated insulin, cortisol and ghrelin profiles [61].

These data indicate that some individuals are more prone to overeating than others. These phenotypes, and certainly others, present signs for reduced appetite sensitivity, but they are not an essentially characteristic of a weakened appetite control. In the current 'obesogenic environment', it is imperative to limit overeating as it may further perpetuate dysfunction in the satiation/satiety control system, creating an unhealthy cycle of poor control on food intake. Indeed, overeating increases circulating leptin levels [62], which may lead to leptin resistance [63] and deplete ghrelin profiles [64]. Also, the satiety insensitivity to overconsumption observed among reduced-obese individuals compared to thin controls is an indication that some aspects of satiety may not improve with weight loss [51]. Specific strategies that focus on enhancing internal appetite sensations could be particularly important for individuals expressing a phenotype more susceptible to overeating.

\section{Preventing Overconsumption in the Obesogenic Environment?}

The answer to this question is not simple considering that food intake is under the influence of homeostatic, hedonic and circadian processes. While it is impossible to completely eliminate environmental cues, one approach to prevent overconsumption is an intervention aimed to enhance homeostatic signals of satiation and satiety and to entrain appetitive rhythms. Such an intervention is attractive for individuals with an underlying susceptibility to overeating or in a weight loss context where appetitive changes, such as decreases in leptin, insulin, and increases in hunger, increase the risk of overeating and weight regain [65-67]. The objective of this intervention would not necessarily be "weight loss" per se, but rather an increase in appetite sensation feelings to help control energy intake at each eating occasion. The following section will present nutritional strategies and behavioral approaches that could be included in an intervention that targets homeostatic and circadian control of eating, with specific attention to satiation and satiety.

\section{Clinical Strategies to Prevent Overconsumption}

\section{Nutritional Strategies to Decrease the Risk of Overeating}

Food composition can influence the control of eating. Protein is widely known to be the most satiating macronutrient [68]. There is now convincing evidence that meals high in protein are more satiating in the short-term when compared to meals lower in protein, i.e., they prolong satiety, and reduce energy intake at a subsequent meal [69]. Consuming a minimum of $20 \mathrm{~g}$ of protein 30 minutes before a meal seems to represent the most effective strategy to enhance satiety, with seemingly no effect of protein on satiation [70]. However, the impact of protein on satiation has not been overly studied and more research is needed. Over the long term, even though the impact of a high protein diet on weight loss is not superior to other diets [71], recent evidence indicates that the use of a high protein diet could be an effective strategy to prevent weight regain $[72,73]$. Moreover, the effect of protein on satiety is nutrientspecific (different proteins cause different effects) and seems to be due to increased diet-induced thermogenesis, specifically with animal protein [74], and/or their influence on meal-induced anorexic gut peptides (GLP-1 and PYY release) $[75,76]$. Thus, ingesting protein before or in a meal may represent one important nutritional strategy that can be used to enhance satiety.

Food properties can also play an important role in influencing satiation and satiety. The short-term impact of energy density (energy per unit weight) on satiation, satiety and energy intake is the most studied nutritional strategy in this category [77]. Because individuals tend to eat a consistent weight of food, reducing the energy density will spontaneously reduce the energy intake of the meal [77]. With respect to satiety, low energy dense foods can be used to reduce energy intake at a subsequent meal. For example, eating a low energy dense soup or salad before a meal (15 to $20 \mathrm{~min}$ ) has been shown to reduce food intake during the meal $[78,79]$. Variations in energy density can be easily achieved by manipulating the proportion of fruit/vegetable 
in or at a meal since they contain more water and fiber. The mechanisms underlying the response to variations in energy density are not well understood but could involve sensory factors related to food volume which influence gastric distension and gastric emptying rate, or cognitive factors, such as beliefs about the satiating capacity of different foods [77]. In summary, this strategy effectively increases satiation and satiety and decreases energy intake and thus, could prevent overeating episodes.

Other food properties or functional agents can influence satiation and satiety and/or create a spontaneous decrease in energy intake. Even though for some there is less evidence, or even contradictions, their potential influence on homeostatic control of food intake merits some attention. Table 1 describes these food properties and functional agent as well as the suspected underlying mechanisms. Among these are pre- and probiotics and their potential role in body weight management. It has been hypothesized that gut microbiota may influence appetite and satiety through a brain-gut axis [80]; gut microbiota can activate vagal sensory neurons that influence gastrointestinal motility and feeding behavior centrally $[81 \cdot, 82,83]$. In line with this hypothesis, supplementation with prebiotic inulin-type fructans (1 to 12 weeks) can influence appetite sensations, such as fullness and hunger, as well as satiety gut peptides (mainly GLP-1 and PYY) [84]. The impact of probiotics on appetite control has been less studied, yet some clinical interventions have found a beneficial effect in body weight management and glycemic control $[85,86]$. The evidence is limited but the hypothesis of gut microbiota effecting appetite control through the gutbrain axis merits further research to determine their specific role as functional agents and the right posology (quantity, timing, etc.) that influence satiation and satiety. The later is also an issue for other food components or functional agents. The potential negative side effects on health of some functional agents, e.g. increased blood pressure with caffeine [87], should also be considered.

In addition to the individual impact of these nutritional strategies on appetite control, the cumulative effect of more than one strategy in a meal/food on satiation and satiety is also attractive. Our laboratory has tested the impact of a palatable yet satiating meal, a meal that includes the maximum number of nutritional strategies known to influence appetite and food intake, on satiety and spontaneous energy intake in healthy men [88]. The satiating meal was high protein (32\% of total energy content), low energy density $(1.25 \mathrm{kcal} / \mathrm{g})$, high fiber $(9 \mathrm{~g})$, and contained a combination of vitamins and minerals (specifically calcium), and spices
Table 1 Key food components, properties, functional agents, and mechanisms that can help to prevent overeating

\footnotetext{
${ }^{1}$ Limited references, CNS: central nervous system
}

\begin{tabular}{|c|c|c|}
\hline Nutrients & Suggested mechanisms & References ${ }^{1}$ \\
\hline - High protein content & $\begin{array}{l}\text { - Thermogenic effect } \\
\text { - Effect on satiety gut peptides }\end{array}$ & {$[75,119]$} \\
\hline - Low energy density & $\begin{array}{l}\text { - Lowering gastric emptying } \\
\text { - Gastric distension } \\
\text { - Dilution of energy content }\end{array}$ & {$[77]$} \\
\hline - High dietary fiber content & $\begin{array}{l}\text { - Decrease energy density } \\
\text { - Slower eating (more chewing) } \\
\text { - Slows down digestion, gastric emptying } \\
\text { - Delay glucose absorption } \\
\text { (lower glycemic index) } \\
\text { - Affect satiety gut peptides }\end{array}$ & {$[120]$} \\
\hline - Low lipid content & - Decrease energy density & {$[121-124]$} \\
\hline - Low glycemic index & $\begin{array}{l}\text { - Delay glucose absorption } \\
\text { - Affect satiety gut peptides }\end{array}$ & {$[125-128]$} \\
\hline - Minimal alcohol content & $\begin{array}{l}\text { - Affect appetite hormones including } \\
\text { gut peptides }\end{array}$ & [129-132] \\
\hline $\begin{array}{l}\text { - Polyunsaturated fatty acids } \\
\text { (e.g., omega-3) } \\
\text { - Optimal level of vitamins and minerals }\end{array}$ & $\begin{array}{l}\text { - Thermogenic effect } \\
\text { • Energy metabolism efficiency }\end{array}$ & {$[135,136]$} \\
\hline - High calcium & - Thermogenic effect & {$[137]$} \\
\hline - Pre and probiotics & $\begin{array}{l}\text { - Vagal neuronal signals - CNS } \\
\text { - Affect satiety gut peptides }\end{array}$ & {$[80,84]$} \\
\hline - Spices (e.g. Capsaicin) & - Thermogenic effect & {$[87]$} \\
\hline - Caffeine & - Thermogenic effect & {$[87]$} \\
\hline - Catechins - green the & - Thermogenic effect & [87] \\
\hline
\end{tabular}


(e.g., capsaicin). As a main course, this satiating meal decreased hunger and increased fullness after the meal and decreased energy intake at the subsequent meal (ad libitum dessert) (- $744 \mathrm{~kJ})$ more than a control meal, with no energy compensation at the subsequent meal. Most notably, these effects were observed without compromising the palatability of the functional food. This point is very important since palatability is known to be an important determinant of food intake in humans [89] and developing palatable yet satiating foods can be very challenging [90]. Over the long term, the consumption of a highly satiating diet (one satiating meal/ day for 16 weeks) also resulted in greater weight loss, improvements in body composition, and favored adherence compared to a conventional healthy control diet [91]. Moreover, the highly satiating diet improved satiety efficiency which was accentuated among those characterized with a weak baseline satiety response (LSP), despite similar weight losses between the two phenotypes. Thus, the satiating meals/diet seem to improve satiety signals beyond what would be expected with a conventional healthy diet, and moreso in a vulnerable phenotype such as in the LSP.

Taken together, the available literature suggests that many food components, food properties or and functional agents could help reduce the risk of overeating. The effects of a highly satiating meal/diet reveal that combining different satiating strategies can improve satiety efficiency, particularly in more vulnerable phenotypes. Over time, this could result in fewer episodes of overeating and a gradual improvement of long-term body weight regulation.

\section{Behavioral Strategies in the Prevention of Overeating}

In addition to nutritional strategies, behavioral strategies, such as exercise, sleep and regular meal patterns, could be used to enhance homeostatic control, both in the short- and long-term, and could influence circadian control of eating and homeostatic hormone profiles.

\section{Physical Activity}

In the 1950s, Mayer hypothesized that exercise can indirectly influence energy intake through its effect on appetite control [92]. Although the biological and behavioral responses to exercise are variable [93], there is a general consensus that exercise has either no effect or can induce a transient post meal suppression of appetite (hunger), even if this does not necessarily translate into a decrease in subsequent food intake [94]. Evidence also shows that, contrary to what may be expected, few intervention studies report an increase in energy intake after exercise, with the majority reporting no effect [95]. In fact, regular physical activity can improve appetite control sensitivity and regular exercisers are better than nonexercisers at detecting differences in preload energy content
[96-98]. Exercise may even have a dual impact on appetite control. Accordingly, a 12-week exercise program increased fasting and daily hunger and increased immediate and delayed satiety quotients, a marker of satiety efficiency, independent of weight loss [99] and which was mediated by changes in appetite peptides [100]. As suggested by King and colleagues [99], exercise may increase in the overall (orexigenic) drive to eat and a concomitant increase in the satiating efficiency after a fixed meal, thus increasing sensitivity to appetite control.

The mechanisms by which exercise improves appetite control are not fully understood. Alterations in gastric emptying rate, gut peptide secretions and substrate oxidation may be involved [94]. Although somewhat inconsistent and understudied, acute strenuous exercise may delay gastric emptying rate whereas exercise at lower intensities may increase it [94]. Some studies found a decrease in AG (acylated-ghrelin) after exercise and a post-exercise increase in the anorexic peptides peptide YY (PYY), GLP-1 and pancreatic polypeptide (PP) [99]. Moreover, exercise-induced changes in substrate metabolism (i.e., fatty acid or $\mathrm{CHO}$ oxidation) are another possible explanation of the impact of exercise on appetite control (for more details, see [94]).

Exercise could also affect appetite indirectly through circadian synchronization. A recent study has shown that increased physical activity is beneficial to circadian synchronization in children (higher bedtime melatonin concentrations and a more efficient reduction in oral body temperature) [101]. Exercise may also act as a zeitgeber, i.e., it can entrain the circadian rhythm by producing either phase advances or phase delays depending on the timing $[102,103]$. Along these lines, a 12-week exercise intervention has been shown to increased morning (fasting) acylated ghrelin levels with a concomitant increase in hunger during this time [100]. Although increasing hunger sensations in the general obese population may not be beneficial, increasing morning hunger sensations in individuals who have a delayed pattern of eating such as in those with NES may aid in shifting energy intake to earlier daytime hours and/or enhance satiety efficiency among those with a reduced satiety responsivity.

Exercise, through the modulation of gut peptides, gastric motility, substrate oxidation and circadian rhythms, may enhance sensitivity to appetite signals which is noteworthy when considering an intervention aimed to decrease overeating susceptibility among individuals with altered appetite responsivity. However, because there is variability in energy-related responses to exercise, it is important to keep in mind that the beneficial impact of exercise on appetite control may not be observed in all individuals. Yet, exercise can still improve other aspects of health, including preventing some negative effects induced by some functional agents (e.g., increase in blood pressure with caffeine) [87]. Physical activity can play a role in modifying feeding behaviors and in enhancing internal signals of appetite control. 


\section{Sleep Patterns}

Recent cumulative evidence also suggests that sleep patterns should also be considered in appetite control as sleep affects both homoeostatic and circadian systems. Recent studies indicate that insufficient sleep decreases plasma leptin levels, increases plasma ghrelin and cortisol levels, alters glucose homeostasis and activates the orexin system, all of which affect appetite control [104]. Accordingly, short sleep duration, per se, is cross-sectionally and prospectively related to increased body weight and body weight gains (see [57] for review) and lack of sleep also seems to compromise the efficacy of weight loss dietary intervention [105]. Although there exist few (if any) interventions which aim to increase sleep duration or to enhance sleep quality, a recent epidemiological study has shown that increasing sleep duration over time is protective against gains in adiposity [106]. If shortduration sleep and reduced sleep quality have a consistent negative impact on appetite control and body weight, it can be hypothesized that improving these, if possible, may have beneficial effects on homeostatic and circadian aspects of appetite control. However, to our knowledge, this has not yet been studied. It should be noted that because sleep is so tightly linked with the circadian system, it is difficult to tease apart their independent effects on health [107] and what enhances sleep will likely enhance circadian synchronization and vice-versa.

\section{Regular Eating Patterns}

Although an understudied area, meal patterns and timing may also influence appetite control. Eating during times of reduced satiety responsiveness, i.e., in the evening, when food intake during this time increases overall daily intake [28] and when satiety responsiveness is low (see section on circadian control of food intake), has been associated with obesity [108, 109]. In addition, overeating without strict meal times has been shown to obliterate the preprandial ghrelin surges in sheep [64] and grazing, i.e., continuous eating [110], reduces hunger in humans without reducing energy intake [111]. Since ghrelin is a key hormone in meal initiation, this irregular eating pattern could weaken appetite control. On the contrary, because preprandial rise in ghrelin is determinant of habitual meal patters and it can be entrained [24], it could be hypothesized that structuring regular meal times, particularly to daytime periods, could help entrain appetite hormones, enhance appetite sensations and phase-shift feeding to earlier times. This is a novel concept, but not without some evidence. One group has observed increased diet-induced thermogenesis and lower energy intake with reduced meal-related insulin responses in regular vs. irregular eating patterns [112]. However, the reduction in energy intake was not replicated in an additional study [113] and in both studies, there were no differences in subjective appetite sensation responses to a meal yet appetite peptides were not measured. Although structuring meals in a temporal manner in order to enhance appetite sensitivity remains to be tested, irregular eating episodes may be deleterious to appetite control and energy intake among individuals who already express low perceived appetite sensations.

These results indicate that exercise, and regular sleep and eating patterns combined with satiating nutritional strategies has the potential to influence homeostatic and circadian control of food intake and prevent overconsumption. As depicted in Fig. 1, short- and long-term processes involved in energy homeostasis influence food intake. These processes can be influenced, in turn, but the circadian system and which can potentially be enhanced through the aforementioned behavioral strategies.

\section{Targeting Internal Biological Processes to Prevent Overeating: Is it Enough?}

Preventing overeating solely through homeostatic and circadian processes seems only to represent one part of the solution. It is largely recognized that the hedonic system is implicated in overeating, particularly in the current environment of unlimited access to a high variety of highly palatable and energy dense foods [114]. Even when sated,

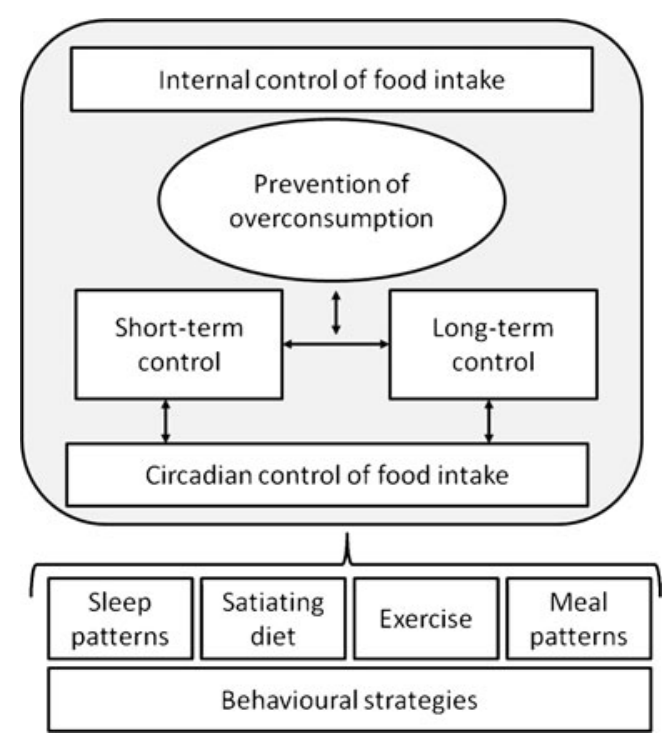

Fig. 1 Factors involved in short-term and long-term control of food intake influence overeating. Some of these factors are also under circadian control, which indirectly implicates the circadian system in overconsumption. Specific behavioral strategies that focus on appetite control and the circadian system may help reduce the extent and frequency of overconsumption 
individuals will continue to eat palatable foods [115]. Thus, an imbalance between the hedonic and homeostatic processes favoring the former is also likely to play a large role in passive overconsumption [1]. Thus, trying to reduce overconsumption should also implicate hedonic pathway. Lastly it is important to emphasize that because satisfaction during and after a meal results from a complex interaction of internal and external environmental factors [116], adequate prevention of overeating also requires the presence of psychological strategies aimed to increase the awareness of satiation and satiety $[117,118]$. Thus, a multidisciplinary approach targeting both homeostatic and hedonic processes as well as circadian control may increase the likelihood of preventing overeating.

\section{Conclusion}

In a context where there are many opportunities to eat beyond our bodily needs and where our obesogenic environment is part of our industrialized society, it is important to develop specific interventions that have the potential to enhance internal control of food intake. This is particularly important in more susceptible phenotypes such as the low satiety phenotype, disinhibited individuals or night-eaters. The results presented in this article indicate that nutritional and behavioral strategies have the potential to influence short-term and long-term homeostatic signals and possibly circadian rhythms. Combined in one specific intervention, these results suggest that it has the potential to enhance homeostatic and circadian signals, to improve satiation and satiety and thus decrease the risk of overeating. More clinical research on the short- and long-term impact of these combined strategies on appetite control and weight gain is needed, particularly in more susceptible phenotypes.

Disclosure Conflicts of interest: V. Drapeau: has received grant support from Danone, Producteurs laitiers du Canada; has received travel/accommodations expenses covered or reimbursed from Pepsico Nutrition congress in Monterrey, Mexico; A.R. Gallant: none.

\section{References}

Papers of particular interest, published recently, have been highlighted as:

- Of importance

1. Swinburn BA, Sacks G, Hall KD, McPherson K, Finegood DT, Moodie ML, et al. The global obesity pandemic: shaped by global drivers and local environments. Lancet. 2011;378(9793):804-14. doi:S0140-6736(11)60813-1 10.1016/S0140-6736(11)60813-1.
2. Saper CB, Chou TC, Elmquist JK. The need to feed: homeostatic and hedonic control of eating. Neuron. 2002;36(2):199-211. doi: S0896627302009698.

3. Blundell J. Pharmacological approaches to appetite suppression. Trends Pharmacol Sci. 1991;12(4):147-57.

4. Teff K. Nutritional implications of the cephalic-phase reflexes: endocrine responses. Appetite. 2000;34(2):206-13. doi:10.1006/ appe.1999.0282S0195-6663(99)90282-9.

5. de Graaf C. Texture and satiation: The role of oro-sensory exposure time. Physiol Behav. 2012. doi:S0031-9384(12)00195310.1016/j.physbeh.2012.05.008.

6. Powley TL, Phillips RJ. Gastric satiation is volumetric, intestinal satiation is nutritive. Physiol Behav. 2004;82(1):69-74. doi:10.1016/j.physbeh.2004.04.037S003193840400188X.

7. - Janssen P, Vanden Berghe P, Verschueren S, Lehmann A, Depoortere I, Tack J. Review article: the role of gastric motility in the control of food intake. Aliment Pharmacol Ther. 2011;33 (8):880-94. doi:10.1111/j.13652036.2011.04609.x. This review summarizes the current literature that surrounds the central effects of gastric motility in satiation, satiety and hunger and the association between gastric motility and long-term body weight regulation.

8. Cummings DE, Overduin J. Gastrointestinal regulation of food intake. J Clin Invest. 2007;117(1):13-23. doi:10.1172/JCI30227.

9. Bray GA. Food intake, sympathetic activity, and adrenal steroids. Brain Res Bull. 1993;32(5):537-41. doi:0361-9230(93)90304-T.

10. Blundell J, Finlayson G, Halford JC. Eating Behavior. In: Kopelman PG, Caterson ID, Dietz WH, editors. Clinical Obesity in Adults and Children, Third Edition. Blackwell Publishing Limited; 2010. p. 134-50.

11. Morton GJ, Cummings DE, Baskin DG, Barsh GS, Schwartz MW. Central nervous system control of food intake and body weight. Nature. 2006;443(7109):289-95. doi:nature0502610.1038/ nature 05026.

12. Schwartz MW, Woods SC, Porte Jr D, Seeley RJ, Baskin DG. Central nervous system control of food intake. Nature. 2000;404 (6778):661-71. doi:10.1038/35007534.

13. Cummings DE. Ghrelin and the short- and long-term regulation of appetite and body weight. Physiol Behav. 2006;89(1):71-84 . doi:S0031-9384(06)00230-7 10.1016/j.physbeh.2006.05.022.

14. Matson CA, Ritter RC. Long-term CCK-leptin synergy suggests a role for CCK in the regulation of body weight. Am J Physiol. 1999;276(4 Pt 2):R1038-45.

15. Barrera JG, Sandoval DA, D'Alessio DA, Seeley RJ. GLP-1 and energy balance: an integrated model of short-term and long-term control. Nat Rev Endocrinol. 2011;7(9):507-16. doi: nrendo.2011.7710.1038/nrendo.2011.77.

16. Riedy CA, Chavez M, Figlewicz DP, Woods SC. Central insulin enhances sensitivity to cholecystokinin. Physiol Behav. 1995;58 (4):755-60. doi:0031-9384(95)00108-U.

17. Kreymann B, Williams G, Ghatei MA, Bloom SR. Glucagon-like peptide-1 7-36: a physiological incretin in man. Lancet. 1987;2 (8571):1300-4. doi:S0140-6736(87)91194-9.

18. Ekmekcioglu C, Touitou Y. Chronobiological aspects of food intake and metabolism and their relevance on energy balance and weight regulation. Obes Rev. 2011;12(1):14-25. doi: OBR71610.1111/j.1467-789X.2010.00716.x.

19. Waterhouse J, Minors D, Atkinson G, Benton D. Chronobiology and meal times: internal and external factors. Br J Nutr. 1997;77 Suppl 1:S29-38. doi:S000711459700007X.

20. Cummings DE, Purnell JQ, Frayo RS, Schmidova K, Wisse BE, Weigle DS. A preprandial rise in plasma ghrelin levels suggests a role in meal initiation in humans. Diabetes. 2001;50(8):1714-9.

21. Callahan HS, Cummings DE, Pepe MS, Breen PA, Matthys CC, Weigle DS. Postprandial suppression of plasma ghrelin level is proportional to ingested caloric load but does not predict 
intermeal interval in humans. J Clin Endocrinol Metab. 2004;89 (3):1319-24.

22. Cummings DE, Frayo RS, Marmonier C, Aubert R, Chapelot D. Plasma ghrelin levels and hunger scores in humans initiating meals voluntarily without time- and food-related cues. Am J Physiol Endocrinol Metab. 2004;287(2):E297-304. doi:10.1152/ ajpendo.00582.200300582.2003.

23. Natalucci G, Riedl S, Gleiss A, Zidek T, Frisch H. Spontaneous 24-h ghrelin secretion pattern in fasting subjects: maintenance of a meal-related pattern. Eur J Endocrinol. 2005;152(6):845-50. doi:152/6/84510.1530/eje.1.01919.

24. Frecka JM, Mattes RD. Possible entrainment of ghrelin to habitual meal patterns in humans. Am J Physiol Gastrointest Liver Physiol. 2008;294(3):G699-707. doi:00448.200710.1152/ ajpgi.00448.2007.

25. Jorde R, Burhol PG. Fasting and diurnal plasma PP, and the effect of fasting and somatostatin on postprandial plasma PP. Acta Physiol Scand. 1982;115(4):421-5.

26. Salera M, Giacomoni P, Pironi L, Ustra C, Capelli M, Giorgi A, et al. Circadian rhythm of gastric inhibitory polypeptide (GIP) in man. Metabolism. 1983;32(1):21-4.

27. de Castro JM. Circadian rhythms of the spontaneous meal pattern, macronutrient intake, and mood of humans. Physiol Behav. 1987;40(4):437-46. doi:0031-9384(87)90028-X.

28. de Castro JM. The time of day of food intake influences overall intake in humans. J Nutr. 2004;134(1):104-11.

29. de Castro JM. When, how much and what foods are eaten are related to total daily food intake. Br J Nutr. 2009;102(8):122837. doi:S000711450937164010.1017/S0007114509371640.

30. Goo RH, Moore JG, Greenberg E, Alazraki NP. Circadian variation in gastric emptying of meals in humans. Gastroenterology. 1987;93(3):515-8. doi:S0016508587002579.

31. Gluck ME, Geliebter A, Satov T. Night eating syndrome is associated with depression, low self-esteem, reduced daytime hunger, and less weight loss in obese outpatients. Obes Res. 2001;9(4):264-7.

32. Rosenthal NE, Sack DA, Gillin JC, Lewy AJ, Goodwin FK, Davenport Y, et al. Seasonal affective disorder. A description of the syndrome and preliminary findings with light therapy. Arch Gen Psychiatry. 1984;41(1):72-80.

33. - Garaulet M, Ordovas JM, Madrid JA. The chronobiology, etiology and pathophysiology of obesity. Int J Obes (Lond). 2010;34(12):1667-83. doi:12. This review examines the complex interactions between the circadian system and factors implicated in body weight regulation.

34. Scheer FA, Hilton MF, Mantzoros CS, Shea SA. Adverse metabolic and cardiovascular consequences of circadian misalignment. Proc Natl Acad Sci USA. 2009;106(11):4453-8.

35. Druce MR, Wren AM, Park AJ, Milton JE, Patterson M, Frost G, et al. Ghrelin increases food intake in obese as well as lean subjects. Int J Obes (Lond). 2005;29(9):1130-6. doi:080300110.1038/ sj.ijo.0803001.

36. le Roux CW, Patterson M, Vincent RP, Hunt C, Ghatei MA, Bloom SR. Postprandial plasma ghrelin is suppressed proportional to meal calorie content in normal-weight but not obese subjects. J Clin Endocrinol Metab. 2005;90(2):1068-71. doi:jc.2004121610.1210/jc. $2004-1216$

37. Drapeau V, Hetherington M, Tremblay A. Impact of eating and lifestyle behaviours on body weight: beyond energy value. Handbook of Behaviour, Diet and Nutrition. Springer; 2011. p. 693-706.

38. Barkeling B, King NA, Naslund E, Blundell JE. Characterization of obese individuals who claim to detect no relationship between their eating pattern and sensations of hunger or fullness. Int $J$ Obes (Lond). 2007;31(3):435-9.

39. Drapeau V, Arguin H, Blundell J, Tremblay A. Behavioural and metabolic characterisation of obese men with weak satiety response (abstract). Obes Facts. 2012;5 suppl 1:1-280.
40. Drapeau V, King N, Hetherington M, Doucet E, Blundell J, Tremblay A. Appetite sensations and satiety quotient: predictors of energy intake and weight loss. Appetite. 2007;48(2):159-66.

41. Drapeau V, Blundell J, Therrien F, Lawton C, Richard D, Tremblay A. Appetite sensations as a marker of overall intake. Br J Nutr. 2005;93(2):273-80.

42. Herman CP, Polivy J. A boundary model for the regulation of eating. Res Publ Assoc Res Nerv Ment Dis. 1984;62:141-56.

43. Rolls BJ, Kim-Harris S, Fischman MW, Foltin RW, Moran TH, Stoner SA. Satiety after preloads with different amounts of fat and carbohydrate: implications for obesity. Am J Clin Nutr. 1994;60(4):476-87.

44. Green SM, Delargy HJ, Joanes D, Blundell JE. A satiety quotient: a formulation to assess the satiating effect of food. Appetite. 1997;29(3):291-304. doi:S0195666397900969.

45. Chambers L, Yeomans MR. Individual differences in satiety response to carbohydrate and fat. Predictions from the Three Factor Eating Questionnaire (TFEQ). Appetite. 2011;56(2):31623. doi:S0195-6663(11)00013-4 10.1016/j.appet.2011.01.003.

46. Hays NP, Roberts SB. Aspects of eating behaviors "disinhibition" and "restraint" are related to weight gain and BMI in women. Obesity (Silver Spring). 2008;16(1):52-8.

47. Drapeau V, Provencher V, Lemieux S, Despres JP, Bouchard C, Tremblay A. Do 6-y changes in eating behaviors predict changes in body weight? Results from the Quebec Family Study. Int J Obes Relat Metab Disord. 2003;27(7):808-14.

48. Bryant EJ, King NA, Blundell JE. Disinhibition: its effects on appetite and weight regulation. Obes Rev. 2008;9(5):409-19.

49. van Strien T, Cleven A, Schippers G. Restraint, tendency toward overeating and ice cream consumption. International Journal of Eating Disorders. 2000;28(3):333-8.

50. Blundell JE, Stubbs RJ, Golding C, Croden F, Alam R, Whybrow $\mathrm{S}$, et al. Resistance and susceptibility to weight gain: individual variability in response to a high-fat diet. Physiol Behav. 2005;86 (5):614-22.

51. Cornier MA, Grunwald GK, Johnson SL, Bessesen DH. Effects of short-term overfeeding on hunger, satiety, and energy intake in thin and reduced-obese individuals. Appetite. 2004;43(3):253-9.

52. Therrien F, Drapeau V, Lupien SJ, Beaulieu S, Dore J, Tremblay A, et al. Awakening cortisol response in relation to psychosocial profiles and eating behaviors. Physiol Behav. 2008;93(1-2):2828. doi:S0031-9384(07)00357-5 10.1016/j.physbeh.2007.08.019.

53. Burton-Freeman BM, Keim NL. Glycemic index, cholecystokinin, satiety and disinhibition: is there an unappreciated paradox for overweight women? Int J Obes (Lond). 2008;32(11):1647-54. doi:ijo200815910.1038/ijo.2008.159.

54. Gallant AR, Tremblay A, Perusse L, Bouchard C, Despres JP, Drapeau V. The Three-Factor Eating Questionnaire and BMI in adolescents: results from the Quebec Family Study. Br J Nutr. 2010;7:1-6.

55. Taheri S, Lin L, Austin D, Young T, Mignot E. Short sleep duration is associated with reduced leptin, elevated ghrelin, and increased body mass index. PLoS Med. 2004;1(3):e62.

56. Knutson KL, Van Cauter E. Associations between sleep loss and increased risk of obesity and diabetes. Ann N Y Acad Sci. 2008;1129:287-304. doi:10.1196/annals.1417.0331129/1/287.

57. Spiegel K, Tasali E, Leproult R, Van Cauter E. Effects of poor and short sleep on glucose metabolism and obesity risk. Nat Rev Endocrinol. 2009;5(5):253-61.

58. Mullington JM, Chan JL, Van Dongen HP, Szuba MP, Samaras J, Price NJ, et al. Sleep loss reduces diurnal rhythm amplitude of leptin in healthy men. J Neuroendocrinol. 2003;15(9):851-4. doi:1069.

59. Stunkard AJ, Grace WJ, Wolff HG. The night-eating syndrome; a pattern of food intake among certain obese patients. Am J Med. 1955;19(1):78-86. 
60. Allison KC, Lundgren JD, O'Reardon JP, Geliebter A, Gluck ME, Vinai $\mathrm{P}$, et al. Proposed diagnostic criteria for night eating syndrome. Int J Eat Disord. 2010;43(3):241-7.

61. Goel N, Stunkard AJ, Rogers NL, Van Dongen HP, Allison KC, O'Reardon JP, et al. Circadian rhythm profiles in women with night eating syndrome. J Biol Rhythms. 2009;24(1):85-94.

62. Levine JA, Eberhardt NL, Jensen MD. Leptin responses to overfeeding: relationship with body fat and nonexercise activity thermogenesis. J Clin Endocrinol Metab. 1999;84(8):2751-4.

63. Klok MD, Jakobsdottir S, Drent ML. The role of leptin and ghrelin in the regulation of food intake and body weight in humans: a review. Obes Rev. 2007;8(1):21-34. doi: OBR27010.1111/j.1467-789X.2006.00270.x.

64. Sugino T, Yamaura J, Yamagishi M, Ogura A, Hayashi R, Kurose $\mathrm{Y}$, et al. A transient surge of ghrelin secretion before feeding is modified by different feeding regimens in sheep. Biochem Biophys Res Commun. 2002;298(5):785-8. doi:S0006291X0202572X.

65. Chaput JP, Pelletier C, Despres JP, Lemieux S, Tremblay A. Metabolic and behavioral vulnerability related to weight regain in reduced-obese men might be prevented by an adequate dietexercise intervention. Appetite. 2007;49(3):691-5. doi:S01956663(07)00317-0 10.1016/j.appet.2007.06.006.

66. Doucet E, Imbeault P, St-Pierre S, Almeras N, Mauriege P, Richard $\mathrm{D}$, et al. Appetite after weight loss by energy restriction and a low-fat diet-exercise follow-up. Int J Obes Relat Metab Disord. 2000;24(7):906-14.

67. Gilbert JA, Drapeau V, Astrup A, Tremblay A. Relationship between diet-induced changes in body fat and appetite sensations in women. Appetite. 2009;52(3):809-12.

68. Paddon-Jones D, Westman E, Mattes RD, Wolfe RR, Astrup A, Westerterp-Plantenga M. Protein, weight management, and satiety. Am J Clin Nutr. 2008;87(5):1558S-61S. doi:87/5/1558S.

69. Halton TL, Hu FB. The effects of high protein diets on thermogenesis, satiety and weight loss: a critical review. J Am Coll Nutr. 2004;23(5):373-85. doi:23/5/373.

70. Abou-Samra R, Keersmaekers L, Brienza D, Mukherjee R, Mace $\mathrm{K}$. Effect of different protein sources on satiation and short-term satiety when consumed as a starter. Nutr J. 2011;10:139. doi:14752891-10-139 10.1186/1475-2891-10-139.

71. Astrup A, Meinert Larsen T, Harper A. Atkins and other lowcarbohydrate diets: hoax or an effective tool for weight loss? Lancet. 2004;364(9437):897-9. doi:10.1016/S0140-6736(04)16986-9 S0140673604169869.

72. Lejeune MP, Kovacs EM, Westerterp-Plantenga MS. Additional protein intake limits weight regain after weight loss in humans. $\mathrm{Br}$ J Nutr. 2005;93(2):281-9. doi:S000711450500036X.

73. Larsen TM, Dalskov SM, van Baak M, Jebb SA, Papadaki A, Pfeiffer AF, et al. Diets with high or low protein content and glycemic index for weight-loss maintenance. $\mathrm{N}$ Engl $\mathrm{J}$ Med. 2010;363(22):2102-13. doi:10.1056/NEJMoa1007137.

74. Westerterp-Plantenga MS. The significance of protein in food intake and body weight regulation. Curr Opin Clin Nutr Metab Care. 2003;6(6):635-8. doi:10.1097/01.mco.0000098087.40916.c4.

75. Veldhorst M, Smeets A, Soenen S, Hochstenbach-Waelen A, Hursel R, Diepvens K, et al. Protein-induced satiety: effects and mechanisms of different proteins. Physiol Behav. 2008;94(2):300 7. doi:S0031-9384(08)00005-X 10.1016/j.physbeh.2008.01.003.

76. Westerterp-Plantenga MS, Nieuwenhuizen A, Tome D, Soenen S, Westerterp KR. Dietary protein, weight loss, and weight maintenance. Annu Rev Nutr. 2009;29:21-41.

77. Rolls BJ. The relationship between dietary energy density and energy intake. Physiol Behav. 2009;97(5):609-15. doi:S00319384(09)00122-X 10.1016/j.physbeh.2009.03.011.

78. Flood JE, Rolls BJ. Soup preloads in a variety of forms reduce meal energy intake. Appetite. 2007;49(3):626-34. doi:S01956663(07)00276-010.1016/j.appet.2007.04.002.
79. Rolls BJ, Roe LS, Meengs JS. Salad and satiety: energy density and portion size of a first-course salad affect energy intake at lunch. J Am Diet Assoc. 2004;104(10):1570-6. doi:10.1016/ j.jada.2004.07.001S0002822304011320.

80. Tehrani AB, Nezami BG, Gewirtz A, Srinivasan S. Obesity and its associated disease: a role for microbiota? Neurogastroenterol Motil. 2012;24(4):305-11. doi:10.1111/j.1365-2982.2012.01895.x.

81. Collins SM, Surette M, Bercik P. The interplay between the intestinal microbiota and the brain. Nat Rev Microbiol. 2012;10 (11):735-42. doi:nrmicro287610.1038/nrmicro2876. This review describes the recent evidence of the gut-brain axis and its influence on behaviour and its implication in disease.

82. Goehler LE, Gaykema RP, Opitz N, Reddaway R, Badr N, Lyte M. Activation in vagal afferents and central autonomic pathways: early responses to intestinal infection with Campylobacter jejuni. Brain Behav Immun. 2005;19(4):334-44. doi:S0889-1591 (04)00127-810.1016/j.bbi.2004.09.002.

83. Lyte M, Li W, Opitz N, Gaykema RP, Goehler LE. Induction of anxiety-like behavior in mice during the initial stages of infection with the agent of murine colonic hyperplasia Citrobacter rodentium. Physiol Behav. 2006;89(3):350-7. doi:S0031-9384 (06)00284-810.1016/j.physbeh.2006.06.019.

84. Darzi J, Frost GS, Robertson MD. Do SCFA have a role in appetite regulation? Proc Nutr Soc. 2011;70(1):119-28. doi: S002966511000403910.1017/S0029665110004039.

85. Ilmonen J, Isolauri E, Poussa T, Laitinen K. Impact of dietary counselling and probiotic intervention on maternal anthropometric measurements during and after pregnancy: a randomized placebo-controlled trial. Clin Nutr. 2011;30(2):156-64. doi: S0261-5614(10)00182-210.1016/j.clnu.2010.09.009.

86. Kadooka Y, Sato M, Imaizumi K, Ogawa A, Ikuyama K, Akai Y, et al. Regulation of abdominal adiposity by probiotics (Lactobacillus gasseri SBT2055) in adults with obese tendencies in a randomized controlled trial. Eur J Clin Nutr. 2010;64(6):63643. doi:ejen20101910.1038/ejen.2010.19.

87. Westerterp-Plantenga M, Diepvens K, Joosen AM, Berube-Parent S, Tremblay A. Metabolic effects of spices, teas, and caffeine. Physiol Behav. 2006;89(1):85-91. doi:S0031-9384(06)00054010.1016/j.physbeh.2006.01.027.

88. Poortvliet PC, Berube-Parent S, Drapeau V, Lamarche B, Blundell JE, Tremblay A. Effects of a healthy meal course on spontaneous energy intake, satiety and palatability. Br J Nutr. 2007;97(3):584 90. doi:S000711450738135X10.1017/S000711450738135X.

89. Yeomans MR. Taste, palatability and the control of appetite. Proc Nutr Soc. 1998;57(4):609-15.

90. Van Kleef E, Van Trijp JC, Van Den Borne JJ, Zondervan C. Successful development of satiety enhancing food products: towards a multidisciplinary agenda of research challenges. Crit Rev Food Sci Nutr. 2012;52(7):611-28. doi:10.1080/10408398.2010.504901.

91. Drapeau V, Arguin H, Tremblay A. Impact of a satiating diet on satiety quotient and body weight in obese men - Canadian Society of Nutrition Annual Meeting (abstract). Applied Physiology. Nutrition and Metabolism. 2010;35:373.

92. Mayer J, Roy P, Mitra KP. Relation between caloric intake, body weight, and physical work: studies in an industrial male population in West Bengal. Am J Clin Nutr. 1956;4(2):169-75.

93. Hopkins M, King NA, Blundell JE. Acute and long-term effects of exercise on appetite control: is there any benefit for weight control? Curr Opin Clin Nutr Metab Care. 2010;13(6):635-40. doi:10.1097/MCO.0b013e32833e343b.

94. King NA, Horner K, Hills AP, Byrne NM, Wood RE, Bryant E, et al. Exercise, appetite and weight management: understanding the compensatory responses in eating behaviour and how they contribute to variability in exercise-induced weight loss. Br J Sports Med. 2012;46(5):315-22. doi:bjsm.2010.08249510.1136/ bjsm.2010.082495. 
95. Blundell JE, King NA. Physical activity and regulation of food intake: current evidence. Med Sci Sports Exerc. 1999;31(11 Suppl):S573-83.

96. Long SJ, Hart K, Morgan LM. The ability of habitual exercise to influence appetite and food intake in response to high- and lowenergy preloads in man. Br J Nutr. 2002;87(5):517-23. doi:10.1079/BJNBJN2002560S0007114502000855.

97. Martins C, Truby H, Morgan LM. Short-term appetite control in response to a 6-week exercise programme in sedentary volunteers. Br J Nutr. 2007;98(4):834-42. doi:S000711450774922X10.1017/ S000711450774922X

98. Van Walleghen EL, Orr JS, Gentile CL, Davy KP, Davy BM. Habitual physical activity differentially affects acute and shortterm energy intake regulation in young and older adults. Int $\mathrm{J}$ Obes (Lond). 2007;31(8):1277-85. doi:080357910.1038/ sj.ijo.0803579.

99. King NA, Caudwell PP, Hopkins M, Stubbs JR, Naslund E, Blundell JE. Dual-process action of exercise on appetite control: increase in orexigenic drive but improvement in meal-induced satiety. Am J Clin Nutr. 2009;90(4):921-7. doi: ajcn.2009.2770610.3945/ajen.2009.27706.

100. Martins C, Kulseng B, King NA, Holst JJ, Blundell JE. The effects of exercise-induced weight loss on appetite-related peptides and motivation to eat. J Clin Endocrinol Metab. 2010;95 (4):1609-16. doi:jc.2009-208210.1210/jc.2009-2082.

101. Shibata M, Tanida K, Shibata S, Kuzuhara K, Shimamoto H, Wakamura T. Effects of Daily Physical Activity Level on Circadian Rhythm of Oral Body Temperature and Melatonin in Children. Journal of Strength and Conditioning 2011;25(S1).

102. Atkinson G, Edwards B, Reilly T, Waterhouse J. Exercise as a synchroniser of human circadian rhythms: an update and discussion of the methodological problems. Eur J Appl Physiol. 2007;99(4):331-41. doi:10.1007/s00421-006-0361-z.

103. Mistlberger RE, Skene DJ. Nonphotic entrainment in humans? J Biol Rhythms. 2005;20(4):339-52. doi:20/4/33910.1177/ 0748730405277982.

104. Leproult R, Van Cauter E. Role of sleep and sleep loss in hormonal release and metabolism. Endocr Dev. 2010;17:11-21. doi:00026252410.1159/000262524.

105. Nedeltcheva AV, Kilkus JM, Imperial J, Schoeller DA, Penev PD. Insufficient sleep undermines dietary efforts to reduce adiposity. Ann Intern Med. 2010;153(7):435-41

106. Chaput JP, Despres JP, Bouchard C, Tremblay A. Longer sleep duration associates with lower adiposity gain in adult short sleepers. Int J Obes (Lond). 2012;36(5):752-6. doi:ijo201111010.1038/ ijo.2011.110.

107. Maury E, Ramsey K, Bass J. Slee, circadian rhythm and metabolism. In: Ahima RS, editor. Metabolic Basis of Obesity. New York: Springer; 2011. p. 229-56.

108. Bellisle F. Impact of the daily meal pattern on energy balance. Scandinavia Journal of Nutrition. 2004;48(3):114-8.

109. Gallant AR, Lundgren J, Drapeau V. The night-eating syndrome and obesity. Obes Rev. 2012;13(6):528-36. doi:10.1111/j.1467789X.2011.00975.x

110. Saunders R. "Grazing": a high-risk behavior. Obes Surg. 2004;14 (1):98-102. doi:10.1381/096089204772787374.

111. Bachman JL, Raynor HA. Effects of manipulating eating frequency during a behavioral weight loss intervention: a pilot randomized controlled trial. Obesity (Silver Spring). 2012;20(5):985-92. doi:oby201136010.1038/oby.2011.360.

112. Farshchi HR, Taylor MA, Macdonald IA. Beneficial metabolic effects of regular meal frequency on dietary thermogenesis, insulin sensitivity, and fasting lipid profiles in healthy obese women. Am J Clin Nutr. 2005;81(1):16-24. doi:81/1/16.

113. Farshchi HR, Taylor MA, Macdonald IA. Decreased thermic effect of food after an irregular compared with a regular meal pattern in healthy lean women. Int J Obes Relat Metab Disord. 2004;28(5):653-60. doi:10.1038/sj.ijo.08026160802616[pii].

114. Erlanson-Albertsson C. How palatable food disrupts appetite regulation. Basic Clin Pharmacol Toxicol. 2005;97(2):61-73. doi:PTOpto 17910.1111/j.1742-7843.2005.pto 179.x.

115. Cornell CE, Rodin J, Weingarten H. Stimulus-induced eating when satiated. Physiol Behav. 1989;45(4):695-704. doi:00319384(89)90281-3.

116. Woods SC. Signals that influence food intake and body weight. Physiol Behav. 2005;86(5):709-16. doi:S0031-9384(05)00399910.1016/j.physbeh.2005.08.060.

117. Provencher V, Begin C, Tremblay A, Mongeau L, Corneau L, Dodin S, et al. Health-At-Every-Size and eating behaviors: 1-year follow-up results of a size acceptance intervention. J Am Diet Assoc. 2009;109(11):1854-61.

118. Daubenmier J, Kristeller J, Hecht FM, Maninger N, Kuwata M, Jhaveri $\mathrm{K}$, et al. Mindfulness Intervention for Stress Eating to Reduce Cortisol and Abdominal Fat among Overweight and Obese Women: An Exploratory Randomized Controlled Study. J Obes. 2011;2011:651936. doi:10.1155/2011/651936.

119. Westerterp-Plantenga MS. Protein intake and energy balance. Regul Pept. 2008;149(1-3):67-9. doi:S0167-0115(08)00069-4 10.1016/j.regpep.2007.08.026.

120. Wanders AJ, van den Borne JJ, de Graaf C, Hulshof T, Jonathan $\mathrm{MC}$, Kristensen M, et al. Effects of dietary fibre on subjective appetite, energy intake and body weight: a systematic review of randomized controlled trials. Obes Rev. 2011;12(9):724-39. doi:10.1111/j.1467-789X.2011.00895.x.

121. Lissner L, Levitsky DA, Strupp BJ, Kalkwarf HJ, Roe DA. Dietary fat and regulation of energy intake in human subjects. Am J Clin Nutr. 1987;46:886-92.

122. Tremblay A, Lavallée N, Alméras N, Allard L, Després JP, Bouchard C. Nutritional determinants of the increase in energy intake associated with a high fat diet. Am J Clin Nutr. 1991;53:1134-7.

123. Tremblay A, Plourde G, Després JP, Bouchard C. Impact of dietary fat content and fat oxidation on energy intake in humans. Am J Clin Nutr. 1989;49:799-805.

124. Yao M, Roberts SB. Dietary energy density and weight regulation. Nutr Rev. 2001;59(8 Pt 1):247-58.

125. Ludwig DS. Dietary glycemic index and obesity. J Nutr. 2000;130(2S Suppl):280S-3S.

126. Roberts SB. Glycemic index and satiety. Nutr Clin Care. 2003;6 (1):20-6.

127. Warren JM, Henry CJ, Simonite V. Low glycemic index breakfasts and reduced food intake in preadolescent children. Pediatrics. 2003;112(5):e414.

128. Bornet FR, Jardy-Gennetier AE, Jacquet N, Stowell J. Glycaemic response to foods: impact on satiety and long-term weight regulation. Appetite. 2007;49(3):535-53. doi:S0195-6663(07)00280210.1016/j.appet.2007.04.006.

129. Tremblay A, St-Pierre S. The hyperphagic effect of high-fat and alcohol persists after control for energy density. Am J Clin Nutr. 1996;63:479-82.

130. Tremblay A, Wouters E, Wenker M, St-Pierre S, Bouchard C, Després J-P. Alcohol and high-fat diet: a combination favoring overfeeding. Am J Clin Nutr. 1995;62:639-44.

131. Yeomans MR, Caton S, Hetherington MM. Alcohol and food intake. Curr Opin Clin Nutr Metab Care. 2003;6(6):639-44. doi:10.1097/01.mco.0000098088.40916.20.

132. Calissendorff J, Gustafsson T, Holst JJ, Brismar K, Rojdmark S. Alcohol intake and its effect on some appetite-regulating hormones in man: influence of gastroprotection with sucralfate. Endocr Res. 2012;37(3):154-62. doi:10.3109/07435800.2012.662662.

133. Lawton CL, Delargy HJ, Brockman J, Smith FC, Blundell JE. The degree of saturation of fatty acids influences post-ingestive satiety. Br J Nutr. 2000;83(5):473-82. doi:S000711450000060X. 
134. Buckley JD, Howe PR. Long-chain omega-3 polyunsaturated fatty acids may be beneficial for reducing obesity-a review. Nutrients. 2010;2(12):1212-30. doi:10.3390/nu2121212 nutrients-02-01212.

135. Doucet E, Després J-P, Bouchard C, Tremblay A. Body weight and composition in consumers and non-consumers of vitamin supplements. Int J Obes Relat Metab Disord. 2000;24(1):S157.
136. Johnston CS. Strategies for healthy weight loss: from vitamin $C$ to the glycemic response. J Am Coll Nutr. 2005;24(3):158-65.

137. Gilbert JA, Joanisse DR, Chaput JP, Miegueu P, Cianflone K, Almeras N, et al. Milk supplementation facilitates appetite control in obese women during weight loss: a randomised, single-blind, placebo-controlled trial. Br J Nutr. 2011;105(1):133-43. doi: S0007114510003119[pii]10.1017/S0007114510003119. 